\title{
Indigenous Food and Tourism for Community Well-Being: A Possible Contributing Way Forward
}

\author{
Dr. Erasmus Mzobanzi Mnguni
}

Head of Department, Hospitality and Tourism Department (Ritson Campus), Durban University of Technology, P. O. Box 1334, Durban, 4000, South Africa

\section{Dr. Andrea Giampiccoli}

Research Associate, Hospitality and Tourism Department (Ritson Campus), Durban University of Technology, P. O. Box 1334, Durban, 4000, South Africa

\section{Doi:10.5901/mjss.2015.v6n3s2p24}

\begin{abstract}
Indigenous food has been recognized as a strategy to enhance community well-being; however its usage is decreasing due to a number of factors. At the same time indigenous food has been linked to issues such as biodiversity, and tourism. Indigenous food link to culinary arts is seen as possible way to revive the usage of indigenous food to enhance community well-being and tourism development. Using these issues as a background this paper aims to propose a possible strategy to contribute to community well-being by using indigenous food as a leverage and pivotal force. This is done by proposing a Teaching and Learning centre for indigenous food and cultural tourism to be developed within a tertiary education institution. Hospitality and tourism students are seen as future personnel that can contribute to the revival of indigenous food. The paper is based on the analysis of available literature that covers and connects the various matters discussed in the analysis such as indigenous food, culinary art and tourism.
\end{abstract}

Keywords: Indigenous food: Tourism; South Africa: Chefs, Culinary arts.

\section{Introduction, Aim and Methods}

The use of leafy vegetables during winter helps to address food shortages at this time. Revival of the use of indigenous leafy vegetables within communities will also ensure a focus on the conservation of these crops while ensuring the availability of diverse genetic material for future needs (Venter, van Rensburg, Voster, van den Heever \& van Zijl, 2007:145).

The increase in tourism volume and a more discerning clientele has spurred the alert of South African's entrepreneurs and the more innovative and adventurous chefs to invest in the development of local cuisine (du Rand, Heath \& Alberts, 2003:101).

An estimate of 'over 7000 species' of plants worldwide can be used for food (Pasquini \& Young, 2009, p. XXI). Nevertheless, there are wide reports on the challenges of food insecurity especially in developing countries since human food consumption is based on a few varieties of crops (Guyomard, Darcy-Vrillon, Esnouf, Marin, Momot, Russel, \& Guillou, 2011:2). Pasquini and Young (2009, P. XXI) attribute the decrease in varieties of crops suitable for human consumption to the Green Revolution. There is therefore a gap between the possible food varieties that can be utilized for human consumption and the actual varieties being consumed. This gap can be linked to food insecurity. Cloete and Idsardi's view (2013, p. 902) is that food insecurity is caused by a relative reduction of crop varieties used for human consumption despite the improvement in agricultural technology. This results in hunger, malnutrition and deaths of humankind. Although Green Revolution brought some positive contributions, it was not suitable for Africa and other marginal territories where "many other varieties of crops continue to play significant roles in traditional farming systems" (Pasquini \& Young, 2009, p. XXI). Food security should advance in context of sustainable development (Guyomard et al., 2011, p. 2).

There is a correlation between culture, indigenous food, food security and nutrition. According to Damman (2005, p. 313) "the respect for indigenous food culture as part of the wider indigenous cultural identity is crucial for indigenous nutritional status and food security". In this context, local food can be holistically utilized for community development and resolve food insecurity challenges. In the last two decades, there has been a growth of interest in the linkages between 
agriculture, environment and the limit of the Green Revolution. A great concern is on the underutilization and neglect of species that can benefit the communities in terms of nutritional food security, income generation, medical value and, suitability for low-input systems for marginal environments (Aphane, Chadha \& Oluoch, 2002, p. 10; Pasquini \& Young, 2009, p. XXI). More comprehensively, local food has been indicated as a contributor to various aspects of development and sustainability. Thus, local crop species can be instrumental in enhancing local food production and community empowerment. Furthermore, local food varieties will enhance the brand of the local community area . In other words, the local food builds a 'brand identity' that will be a tourism attraction and will further generate local pride, and create employment opportunities for local people and so on (see du Rand, Heath \& Alberts, 2003, p. 100). While in the past food related studies did not receive the deserved attention in the literature (Telfer \& Wall, 1996, p. 636), later food has been recognized as an essential element in local cultures and consequently in the promotion of tourist destination which ignites community economic development (Hall, 2003, p. XXI) and tourism related food research has been growing (Eves Sims, 2009, p. 321; Mak, Lumbers \& Eves, 2012, p. 172).

This study considers that community development must be understood beyond strict economic terms and this must include the improvement of the general quality of life (Saayman, 2009, p. 79). This article will, firstly, explore the relevance of indigenous food in enhancing food security, nutrition and biodiversity in communities. Then, an analysis of the linkages between culture, tourism and culinary art will be discussed. The paper will finally propose a possible solution (within a South African tertiary education institution) that could contribute to community well-being through the indigenous food culinary and tourism milieu. The rationale for selecting a developing country is on the need to counteract the ongoing strategies used to resolve food insecurity that persists whilst there is neglect on the role of traditional and indigenous food (Chadare, Hounhouigan, Linnemann, Nout \& van Boekel, 2008,p . 339). The aim of the paper is therefore to propose a possible strategy to contribute to community well-being by using indigenous food as a leverage and pivotal force. The paper is based on the scrutiny of available literature that encompasses and interlinks the various matters discussed in the analysis such as indigenous food, culinary art and tourism.

This introductory section also clarifies the terminology and definitions associated with indigenous food as they can be confusing (Modi, 2003, p. 683; Ambrose-Oji, 2009, p. 10). According to Maundu, Achigan-Dako and Morimoto (2009, p. 66) indigenous (or native) food refers to type of foods "known to be native to or to have originated in a specific geographical location". On another note, traditional (or indigenized) foods refers to food that have been in use for a sufficient length of time to be part of the local food habits, knowledge systems and customs for communities (for indigenized definition see also van Rensberg, van Averbeke, Slabbert, Faber, van Jaarsveld, van Heerden, Wenhold, \& Oelofse, 2007, p. 318). In their study Cloete and Idsardi (2012, p. 2) combined the meaning of the two terms namely indigenous and traditional food and this is their definition: "Indigenous and traditional food crops are defined as vegetables, fruits, nuts and grains that are native to the region and/or that are consumed linked to culture and heritage." In this perspective, local food can be viewed from a more general and tourism angle, thus embracing both terms (indigenous and indigenized). While this paper will mention and consider all various food (indigenous, indigenized and local) specific focus is on indigenous food.

\section{Literature Review}

Linkages between food, nutrition and biodiversity (Nesbitt, McBurney, Broin, \& Beentje, 2010) and cultural values (FAO, 2011, p. 17) are very important. In addition, "food variety also reflects biodiversity and environmental security" (Wahlqvist, no date, p. 2). Furthermore, there is correlation between food diversity, sustainability and biodiversity for human wellbeing from a horticultural perspective in that "horticulture, biodiversity, and nutrition form the trio leading to sustainable diets for current and future generations" (Lutaladio, Burlingame \& Crews, 2010, pp. 481, 484). Indigenous food is produced from indigenous products that are adapted to the local environment and remain within historical patterns of land/natures usages systems (Lutaladio, Burlingame \& Crews, 2010, p. 482).

Sadly, different factors, such as colonialism, have not only contributed to the change of food patterns in the previously colonized spaces but have also contributed to the loss of indigenous food knowledge (McCann, 2010, p. 26; see also Raschke \& Cheema, 2007 for factors that impacted on nutrition transition in parts of Africa). Religion diversity (O' Connor, 2012, p. 77) and influence of modernization (Langgat, Yasin, \& Mansur, 2011, p. 694) are examples of the causes of change in the production and consumption of indigenous food with often nutritional and/or cultural consequence.

The current world presents a "homogenous food systems of the developed world, where industrialization has reduced the diversity of foods at the intra-species level" (Nesbitt et al., 2010, p. 487; see also Guyomard et al., 2011, p. 9). This is reflected in the emerging and developing countries where the food trend patterns of convergence of eating 
habits are based on Western diet (Kimani-Murage, Kahn, Pettifor, Tollman, Dunger, Gómez-Olivé, \& Norris, 2010, P. 2; Guyomard, et al., 2011, p. 3). Diet transition contributes to the increase of overweight and obesity problems not only in developed countries but also in many developing settings, especially in urban setting (Guyomard, et al., 2011:13). Moreover, in poor communities undergoing nutrition transition, specifically in rural South Africa where children at their early stage of development are malnourished whilst those at adolescent stage experience obesity problems (KimaniMurage et al., 2010, p. 7). A study done by Guyomard et al. (2011:3) ironically states that "by 2050 eating patterns will be a major issue for world food security". Therefore, Westernized diets cannot be generalized throughout the planet. Instead, indigenous food varieties should be encouraged. A research conducted by Smith $(1995$, p. 16) in West Africa concluded on the importance of food variety in achieving optimal human nutrition. However, the homogenization of food habits is not conclusive as consumption patterns are also influenced by geographical differences and various historical factors (Cochrane, 1995 cited in Potter, 2002, p. 192; Flandrin \& Montanari, 1999, p. 551).

Nature provides variety of food to its people depending on the geographical location: however, culture and beliefs influence the choice of food to eat (Flandrin, 1995, p. 15). For example, some of the people in Africa consume certain species of insects while Europeans do not and "French surprise and scandalize their neighbours by eating frogs and snails..." (Flandrin, 1995, p. 15). Therefore, food resembles culture in different geographical locations (Montanari, 2006). Montanari (2006, p. XI) argues that food in all its stages is culture, thus: "Food is culture when it is produced [...] Food is culture when it is prepared [...] Food is culture when it is eaten."

It is therefore vital to consider different aspects of food production, preparation and food choice. According to Montanari (2006, p. XI) the choice of food to eat is influenced by various factors such as the economic and nutritional dimensions of the gesture or symbolic values of food. However, Krebs (2009:707) argues that food preferences are not linked exclusively to culture and personal experience but they are also influences by other factors such as genetics and ecology. It is critical to note that culture remains a common denominator on the choice, production and preparation of food. A research conducted by Lambden, Receveur and Kuhnlein (2007, p. 317) on indigenous women in the Arctic region demonstrates universal perspectives that traditional food has many meaningful attributes that contribute to health and cultural life specifically. Culinary heritage is (form) part of the local identity differentiating each geographical space (Bessiere, 1998, p. 29). Within an African context, for example, (Smith, 1995, pp. 6, 12) states that "West African foods and food habits are part of the people's African rich cultural heritage" however, the search for 'fast food'- like foods in this area indicates that fast food is eroding food culture.

One of the challenges on the use of indigenous food is the negative perception of people on these food varieties. Often indigenous food is regarded as poor people's food and reserved for specific ritual/cultural uses, hence diminishing its possible utilization in the future (Vorster, Jansen van Rensburg, Van Zijl, \& Venter, 2007a and b; Faber, Oelofse, van Jaarsveld, Wenhold, Jansen van Rensburg, 2010, p. 37; Dweba \& Mearns, 2011, pp. 566. 570). Kepe (2008, pp. 534, 544 ), highlights an array of negative perceptions (and associates possible consequences) on traditional food (in this case Imifino - wild edible leaves) such as, amongst others the influence of Western based perspective that weeds need to be eliminated (Imifino is viewed as a weed) and it is underappreciated for its nutritional value by health and nutritionist specialists.

Perceptions of indigenous food are changeable as culture is not static. Thus, it is important to note that perceptions held by people are often cultural based and are embedded in history. Therefore, peoples' perceptions are on the value of indigenous foods such as edible leaves and roots can change positively (Kepe, 2008, p. 544). Traditional food can be reinterpreted in its value and meaning, thus for a wealthier household indigenous foods is no more a necessity but has become a pleasure (Bessiere 1998, p. 25). Therefore, indigenous food can also be eaten for pleasure purposes. Kepe's $(2008$, p. 537) research on wealthy communities find out that, "wild edible leaves only serve as an occasional treat, rather than as part of a regular meal." Local culture can absorb and redefine introduced food products and from a production perspective the insertion "of introduces crops into existing traditional agro-biodiversity systems and local cultures is an indication of the dynamism of local knowledge that allows for growth from external interactions and for cultural evolution" (Shava. O'Donoghue, Kransy, \& Zazu, 2009, p. 7). The consumption of indigenous food should try to exploit the changeable cultural perception of this food. In this regard indigenous food such as leafy vegetables is less eaten, especially by youth, but this can be linked to ignorance and unfamiliarity with the specific food. It is important to reintroduce these indigenous foods as a daily food habit especially in the more urbanized context by the development of new recipes that will increase their consumption (Smith \& Eyzaguirre, 2007, p. 5). A 1940 recipe book with a section of traditional recipes in Lesotho (Dyke, 1940, p. 235) acknowledges a generational gap (and changes), proportionally to their economic status, influenced by Europeans in local people food habits with new ingredients and kitchen utensils. In more recent times the situation is also changing (as above the food usage in wealthier households proposed by Kepe, (2008, p. 537) and somehow a mixed situation and in such circumstances "the transmission of culinary know-how is, 
furthermore, not what it used to be. There is a frittering away of skills. The daughter or granddaughter no longer inherits the secret family recipes, however, going back to the 'culinary roots' is revived, thanks to factors such as process of nostalgia and search of more natural products" (Bessiere, 1998:25)

According to Sims (2012, p. 326) there is a vital link between local food, tourism, and agriculture and food safety. Local food has the potential to play a central role within the sustainable tourism agenda, by encompassing everything from concerns about food safety and the impacts of agriculture on the rural environment to visitor demands for more "authentic" tourist experience." In this context it can be argued that the promotion of culinary heritage encourages the establishments of independent and collective culinary initiatives that will eventually lead to the development of rural tourism" (Bessiere, 1998, p. 29). As indigenous food is not appreciated by locals so is the local cuisine and its value often is underestimated by locals in relation to the tourism potential (du Rand et al., 2003, p. 99). However, it is also the case that in food tourism "local food in the form of regional cuisine is rarely presented as an important resource in publicity material and promotional messages prepared for mainstream tourism" (du Rand et al., 2003, p. 101). The association and collaboration of various stakeholders involved in tourism and hospitality can serve as developers and promoters of local cuisine (see for example Boyne \& Hall, 2004, P. 83; see also Telfer 2000 for a Canadian example).

Chefs and other personnel involved in the tourism and hospitality sector could (should) be involved and be the protagonists of the revitalization of indigenous food. Executive chefs are always regarded as instruments in initiating various local/indigenous culinary projects (Telfer \& wall, 1996). However, chefs and tourists' perceptions and misconceptions can jeopardize the utilization of indigenous crop species. For example, chefs could be reluctant to prepare indigenous food because of their pre-assumptions that tourists will not the indigenous food (Torres, 2002), hence the need to campaign or promote knowledge on the importance of indigenous or local food amongst chefs to enhance the tourist experience (Torres, 2002, p. 303). In Peru, indigenous food has been recognized and values by chefs and restaurateurs and thereafter by the government (Jacoby \& Murillo, 2012). Today, Peru is proud of its Peruvian cuisine which comprises of indigenous food made from local crops by local chefs (Jacoby \& Murillo, 2012, P. 359). However, the Peruvian dishes were once disdained until recently by the Criollo (Creole) ruling and middle class who, as descendants of the Spanish conquerors, tended to reject native cultures in favour of those from Europe (Jacoby \& Murillo, 2012, p. 359). In this context the case of Peru potatoes is a good example where Peruvian chefs and food writer's expanded national attention on indigenous crops/food, formerly focused on three varieties of potatoes found at most supermarkets, at the expense of other hundreds of varieties still being produced by small farmers in Southern Andean communities (Jacoby \& Murillo, 2012, p. 360).

Although the challenges to educate the consumer on new products is recognized, practically exactly the same story has been reported in Australia where through an organization involved in native Plant Food industry, new products from indigenous plants "are finding their way into the kitchens and pantries of innovative cooks and chefs around the country and overseas, bringing with them new flavours and aromas, nutritional benefits and economic opportunities" (ANFIL, 2011). Amongst activities of ANFIL (2011) is the presentation of video with more than 30 recipes used to train young Australian chefs in colleges around Australia to make them "familiar and confident with Australia's own indigenous ingredients." As much the final result can be argues, in Chile chefs are involved in rescuing the culinary heritage of the country together with a group of local Mapuche women (supported by an NGO) to link the possible increase of indigenous foods requirement (due to their introduction in the restaurant menus) to empowerment of women, biodiversity and culinary heritage maintenance (Howard, 2003, pp. 12, 13). Celebrity chefs could be specifically relevant for the influence that they can have on children as children are the next generation hospitality and tourism personnel as much as of producers and consumers of food (Caraher, Baker \& Burns \& 2004, P. 270). The children's' foods learning process is important because, as mentioned by Bosire (2000, p. 176), "food habits are required early in life and once established are long lasting and resistant to change."

\section{The South African Context}

In South Africa, various studies related to indigenous food, especially but not exclusively to indigenous leafy vegetables, has been carried out to address various issues in nutrition, cultural knowledge, economic vale, biodiversity and indigenous food acceptance in children and food transition (Wehmeyer, \& Rose, 1983; Bath \& Rubuluza, 2002; van Rensburg et al., 2007; Vorster et al., 2007 a and b; Bharucha \& Pretty, 2010; Faber et al., 2010; Matenge, Van der Merwe, Kruger, \& De Beer, 2011; Cloete \& Idsardi, 2013:902; van de Hoeven, Osei, Greeff, Kruger, Faber, \& Smuts, 2013). In 1936 and 1974 attention was drawn on nutritional value of 'Native spinaches' or indigenous plants (Fox, 1974; Levy, Weintroub, \& Fox, 1936). In South Africa the possible correlation between indigenous local food and tourism has been proposed (du Rand, et al., 2003, p. 101) and community-based tourism has been specifically investigated as a 
possible contributor to community development (Boonzaaier \& Philip, 2007; Giampiccoli \& Hayward Kalis, 2012). Thus, within a tourism perspective in South Africa "it has become essential to explore opportunities to promote food tourism and more specifically its culinary heritage" (du Rand et al., 2003, p .101). From a tourism perspective, in South Africa, often what is required is change of mentality in relation to indigenous food by some of the stakeholders in the tourism sector, as such Destination Marketing Organizations (DMOs) could need a 'mind shift' in relation to the importance they associate with local food in destination marketing (du Rand et al., 2003, p. 107).

Moreover, indigenous food should be appreciated for its variety of contribution to community development and well-being in faculties such as nutrition, biodiversity, cultural values and so on. In addition the association of indigenous food with tourism should be recognized and valued as a possible contributor to local or community development. A study conducted by (Vorster et al., 2007b, p. 53) concluded that, ignorance and perception on indigenous food can be changed; it therefore, recommends the educating of youth in order to enhance awareness and image of indigenous food. Indigenous food (and drink) awareness needs to be enhanced for better nutrition (Jacobs, 2002, p. 376) and the facilitation of biodiversity (Vorster et al., 2007a and b; see also Van Wyk, 2011, p. 865 for the need to increase awareness of traditional art of brewing to become a possible tourist attraction). Domesticated, wild, indigenous and indigenized foods/ingredients are relevant within a context of diet variety and in addition, cultural and tourism contexts. Wild and indigenous foods should, however, be more prominently revived in their importance as they are the ones mostly suffering stigma and underappreciated.

Recipe about native or indigenous foods has been described since historical stone-age period (Bryant, 1939). Recipes were rich in indigenous ingredients and customized/localized preparation methods. One of the common local beverages recorded in the historical recipe book is 'kaffir-beer' (kaffir was previously used in South Africa to refer to a black person). This is beer prepared from indigenous crops in a customary way. However, with the evolving of generations some sectors in society categorized the indigenous beer as harmful for human consumption as done to other indigenous foods (Bryant, 1939). Some authors rather view 'kaffir-beer' as a very admirable, beneficial, even, perhaps, as a necessary form of food; and Governments in their legislation should recognize this fact, and rather aim at preventing its abuse than preventing its use (Bryant, 1939:9). Coetzee (1982, p. 87) further argues that, variety of local indigenous food prepared from 'veld' crops enhances the diet of local South Africans.

It is therefore vital to revive the South African's indigenous cuisine as the nation is multi-culturally rich. South Africa is home to various cultures including the Khoi Khoi, European settlers and slaves from India, Madagascar, and Indonesia who might have influence in South African cuisine (Snyman 2004). Although it is important to review the impact of other nationalities who settled in South Africa on the local cuisine; most local research has overlooked the relevance of black cuisine to South African culinary history, and it has received scant coverage in cookery books (Snyman, 2004, p. 91). An amalgamation of these various food traditions is what makes South Africa a 'rainbow cuisine' (Snyman, 2004). Rainbow cuisine is not as self-conscious a trend as fusion food, which is so often outré in its combinations. It is, instead, a natural expression of the country's history and of those who contributed to it: the indigenous Khoisan, Xhosa, and Zulu people, among others; and the Portuguese, Dutch, English, and French; and the slaves brought from Java, Sumatra, India, Indonesia, and Madagascar (Goldstein, 2008).

The significance of the 'rainbow cuisine' let the South African Government to consider possible contribution of indigenous food to community development. In 2004 it, therefore, funded a book titles South African Indigenous Foods. A collection of recipes of indigenous foods, prepared by generation of women (Basemzansi, 2004). While the book presents an array of indigenous foods recipes prepared with indigenous and indigenized ingredients (see recipes in Basemzansi, 2004), the South African Government clearly view indigenous food as an important tool of community development and well-being, as well as its role in tourism (see Adam, 2004, p. 9; Moroka, 2004, p. 95; Ngubane, 2004, p. 7; Sonjica, 2004, p. 8). Furthermore, the Government acknowledged the importance of indigenous food in poverty reduction by stating that the Indigenous Food Poverty Alleviation project is primarily about commercializing foods, thereby contributing to poverty alleviation (Moroka, 2004, p. 95). However, the challenge is to promote the use of indigenous food/ingredients making it more accepted. Increasing and improving indigenous food recipes is a possible solution to the challenge. Properly proposed: "The increase in tourism volume and a more discerning clientele has spurred the more alert of South Africa's entrepreneurs and the more innovative and adventurous chefs to invest in the development of local cuisine. The challenge is for this to develop without losing any of the cuisines' fragrance, taste and originality and preventing it from becoming a fusion of confused tastes and flavors with no definite distinction of the various cultures of [South Africa]" (du Rand, et al., 2003:101).

It is therefore vital to arrest the tendency of neglecting the utilization of indigenous foods at the expense of human and community development. A study conducted in South Africa found out that while parents have good knowledge and positive perception of indigenous and traditional plants, their children (school pupils) appreciate eating them although 
they don't have more knowledge on the indigenous plants; indicating "great potential for the promotion of indigenous and traditional plants (ITPS) as a strategy for improved child nutrition" (van der Hoeven, et al., 2013:11). It can be argued that not all is lost but time of action is becoming always more urgent.

\section{A Possible Way Forward}

New directions in tourism show that food is increasing its role in tourism and wine tourism (also referred to as gastronomic tourism, culinary tourism and cuisine tourism) and as such it is becoming relevant part of the tourism sector (Santich, 2004, p. 20). Gastronomic tourism should be seen within the general realm of cultural tourism (Santich, 2004, p. 20). In addition, food, also thanks to its general accessibility, can be used as a teaching tool on culture, as "food can serve as a window into specific cultures and can readily be used to teach concepts about culture, including both specific theoretical models as well research methods" (Long, 2001, p. 235). There is the need, therefore, to enhance the gastronomic/culinary knowledge of students (future hospitality and tourism personnel) to keep pace with new trends in tourism and enhance the tourism experience. A properly advanced:

Given that the students of today are the hospitality mangers of tomorrow who must face and respond to the challenges of the future, their ability to meet these challenges is largely dependent on their education and the content and quality of the current curriculum [...] in order to respond to current trends in tourism, it is important that hospitality education include a significant and relevant gastronomy component, in addition to practical and business or management courses, so that students develop an understanding of the history and culture of food and drink, and in particular, the history, culture and traditions of the products of their particular region or country (Santich, 2004:22, 23).

Indigenous food could be a pivot on which to base this strategy. However, lack of knowledge of local food has been mentioned as an obstacle together with the needs to increase the image (pride) related to local food (du Rand et al., 2003, pp. 108, 110). Greater education and knowledge about local indigenous food, as proposed here, can be a very strong contributing factor to enhance indigenous food pride (thus cultural pride), tourism attractiveness, positive visitor experience while at the same time (parallel to these matters) contribute to nutrition, food security, biodiversity and other community well-being matters.

Therefore, the establishment of a Teaching and learning centre for indigenous food and cultural tourism (thereafter 'The Centre') within a Hospitality and Tourism Department of a tertiary education institution as strategy to enhance the role and value of indigenous foods is here proposed. The Centre will focus on indigenous foods, but at the same time not neglecting issues of biodiversity and nutrition (for example, in the facilitation of an indigenous vegetable/plants nursery). The Centre will focus on a indigenous culinary and cultural perspective linked together with cultural tourism and at the same time taking into consideration nutritional values of food. At the same time, while the main focus will be, for logistical reasons, on South African indigenous cuisine and food, indigenous food will be understood on a global perspective. Thus, indigenous cuisine and food from other geographical context will be acknowledged and considered in the centre activities. The aim is to increase/improve indigenous food recipes and pride to be more widely accepted and with positive effects on nutritional, cultural and general well-being on the population. At the same time indigenous foods will be regarded more positively and contributed, as an important cultural attraction, to tourism development. Figure 1 proposes an initial possible framework of the roles and outcomes of the Centre. It is here supported that students (future graduates) in the Hospitality and Tourism Department should be seen as the future personnel involved in the hospitality and tourism sector therefore the ones that can influence the role and values of indigenous foods in the hospitality and tourism sectors and society at large.

Figure 1 present a schematic representation of the possible here suggested role and outcomes of the centre. The dotted line shows that tourism will 'push' to fine new recipes to maintain and possibly enhance the attractiveness of indigenous food. The Centre (and the students within it) will work to improve indigenous food recipes to make it more acceptable and tourism attractive while keeping its indigenous flair. Recognition of changes and possible shift from authenticity (for taste and tourism reasons) will have to be acknowledged, to culturally preserve/ distinguish the 'authentic' and 'non authentic' recipes. The new recipes together with the fostering of the value and recognition of indigenous food as a 'pride' element of the culture will work to make indigenous food more accepted in society and a contributing element to cultural tourism. As a positive 'side-effect' the new recipes will contribute to other community development and wellbeing factors such as biodiversity, nutrition and food security. 


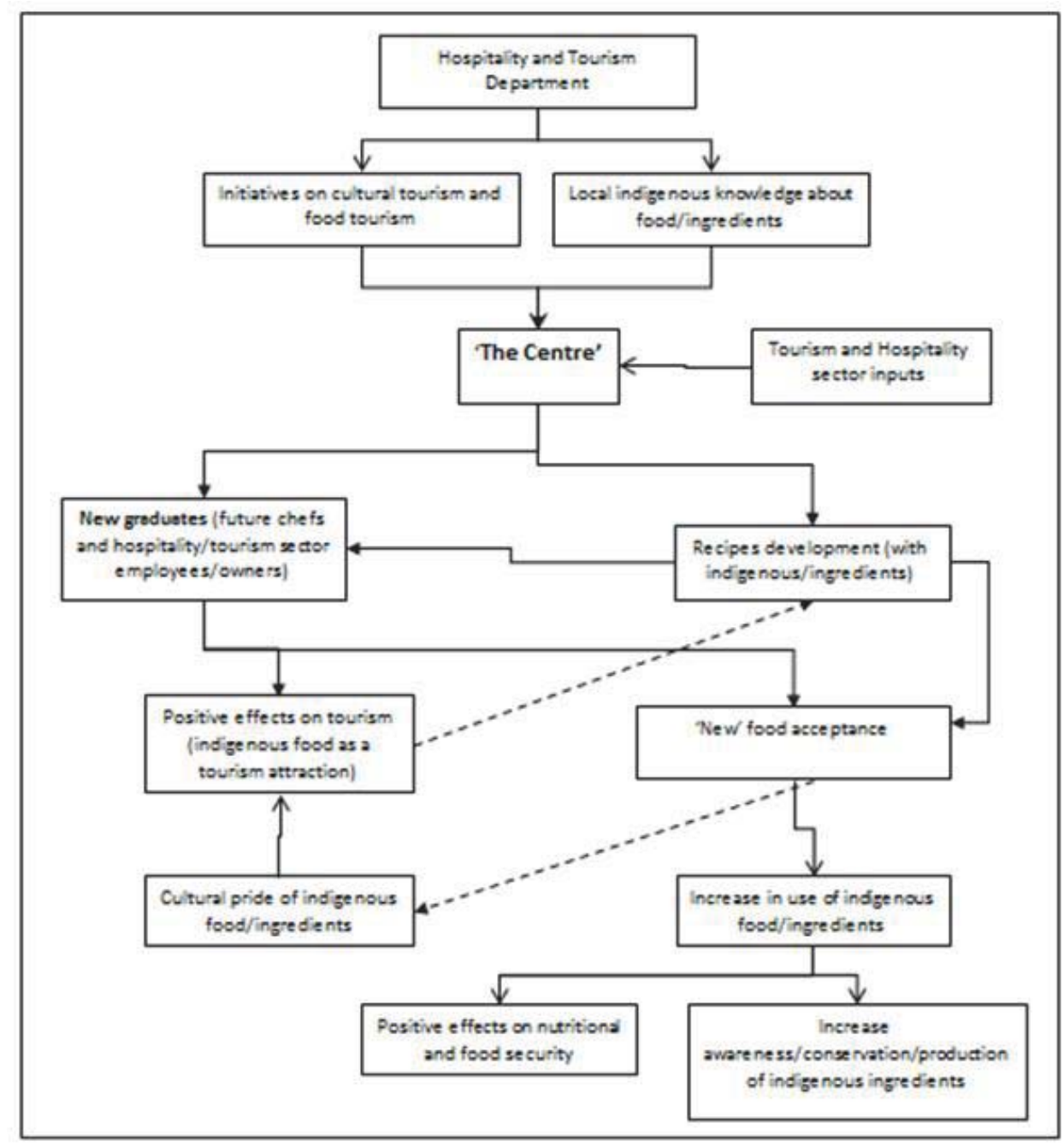

Figure 1: Schematic representation of the Centre roles and outcomes.

It has been proposed that tourism education is not taken seriously and some tourism programmes are very much compromised as they cover a very small percentage of tourism matters in the curriculum (Bhardwaj, Chrishan, Chaudhary, Kumar, Boora, Chand, \& Taxak, 2006). Nevertheless tourism education has a role to play towards the upliftment of the tourism industry as well as in the community. The three milieus of tourism, research and teaching with their specific factors such as globalization and behavior of tourism within the tourism milieu are interconnected. Within this context the centrality of the expertise from higher education institution for effective tourism education is recognized (Bhardwaj et al., 2006).

The Centre, through research and development, will produce new knowledge in the form of indigenous commercial recipes that could feature on hotel restaurant menus. In addition, indigenous food recipe books will be compiled and these will provide a fresh culinary and cultural tourism resource for the industry as well as the hospitality and tourism students. While various approaches in management and working of the Centre is possible. Figure 2 proposes a possible management structure - which of course just an initial and indicative idea and it can also be transformed through the inputs of the various stakeholders. 


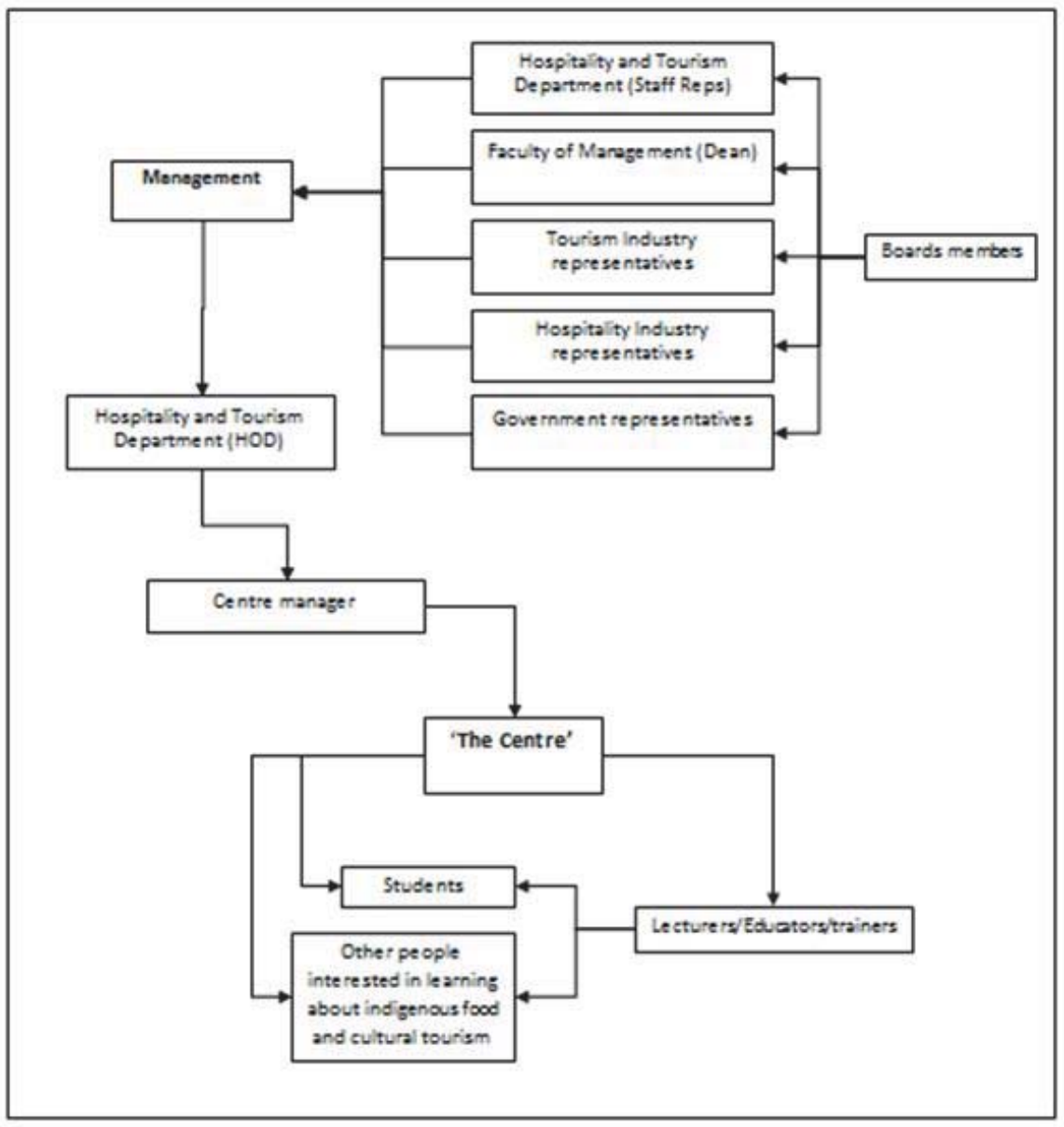

Figure 2: Initial suggestion for Centre management structure

\section{Conclusion}

The paper has suggested the reasons behind the proposed need to establish a Teaching and Learning centre for indigenous and cultural tourism in a tertiary education institution. Various background reasons associated to matters of community development such as food security, nutrition, biodiversity and so on have been briefly discussed as motives behind the need of the Centre. The unfortunate negative perceptions attached to indigenous foods has also been highlighted and proposed as one of the reasons that affect the diminishing utilization of indigenous foods. The specific roles of chefs and other hospitality personnel have been highlighted including their relevance in the hospitality and tourism industries and the influence they could have on the possible behavior of future generations of hospitality and tourism industries personnel, producers and consumers.

It is important to continue to work and find other possible approaches in favour of spreading the values of indigenous foods that encompass, amongst others, culture, environment and health. In this direction the work in new recipes within indigenous foods milieu is seen as a contributor of indigenous food revival and awareness of its roles and values in community well-being. The establishment of the Centre is seen as a possible contributor in the revival and spread of the roles (and values) of indigenous food in community well-being and local economic development. The placement of the centre within a tertiary education institution seems ideal especially if the University has a Hospitality and Tourism Department.

\section{References}

Adam, R. (2004). Foreword by the Director-General: Department of Science and Technology. In B. Basemzansi (Ed.), South African Indigenous Foods. A collection of recipes of indigenous foods, prepared by generation of women (p. 9). Pretoria: IndiZAFoods. 
ANFIL - Australian Native Food Industry Limited, (2011). Available from Wild about Native Foods Marking Five Years of Accomplishment. [Online] Available: http://www.anfil.org.au/wp-content/uploads/ANFIL-Information-Bulletin20Summer-11.pdf (February19, 2014).

Aphane, J., Chadha M. L. \& Oluoch, M. O. (2002). Increasing the consumption of micronutrient-rich foods through production and promotion of indigenous foods. FAO-AVRDC International Workshop Proceedings, 5-8 March 2002, Arusha, Tanzania. AVRDC-the World Vegetable Center, Shanhua, Taiwan.

Basemzansi, B. (2004). In South African Indigenous Foods. A collection of recipes of indigenous foods, prepared by generation of women. Pretoria: IndiZAFoods.

Bath, R. B. \& Rubuluza, T. (2002). The bio-diversity of traditional vegetables of the Transkei region in the Eastern Cape of South Africa. South African Journal of Botany, 68, 94-99.

Bessière, J. (1998). Local Development and Heritage: Traditional Food and Cuisine as Tourist Attractions in Rural Areas. Sociologia Ruralis, 38(1), 21-34.

Bharucha, Z. \& Pretty, J. (2010). The roles and values of wild foods in agricultural systems. Philosophical Transaction of the Royal Society. 365, 2913-2926.

Boonzaaier, C. C. \& Philip, L. (2007). Community-based tourism and its potential to improve living conditions among the Hananwa of Blouberg (Limpopo Province), with particular reference to catering services during winter. Journal of Family Ecology and Consumer Sciences, 35, 26-38.

Boonzaaier, C. C. (2009). The applicability of Government policies to community-based catering services: the Hananwa of Blouber, Limpopo Province. In P. Hottola (Ed.), Tourism Strategies and Local Responses in Southern Africa (pp. 73-89). Wallingford: CAB International.

Bhardwaj, D. S., Chrishan K., Chaudhary, K., Kumar, R.B., Boora, S. S., Chand, M. \& Taxak, R.T (ed.) 2006. Tourism education: An emerging essential. New Delhi: Kanishka Publishers.

Bosire, S. (2000). Catering to young visitors. In J. Akama \& P. Sterry (Eds.), Cultural tourism in Africa: strategies for the new millennium (pp. 175-181). Proceedings of the ATLAS Africa International Conference, December 2000, Mombasa, Kenya. ATLAS Association for Tourism and Leisure Education.

Boyne, S. \& Hall, D. (2004). Place promotion through food and tourism: Rural branding and the role of websites. Place Branding, 1(1), 80-92.

Bryant, A. T. (1939). A description of native foodstuffs and their preparation. Pretoria: The Government Printer.

Caraher, M., Baker, H. \& Burns, M. (2004). Children's views of cooking and food preparation. British Food Journal, 106(4), $255-273$.

Cloete, P. C. \& Idsardi, E. F. (2013). Consumption of Indigenous and Traditional Food Crops: Perceptions and Realities from South Africa. Agroecology and Sustainable Food Systems, 37:8, 902-914.

Coetzee, R. (1982). Funa Food from Africa: Roots of Traditional African Food Culture. Durban: Butterworths.

Damman, S. (2005). The right to food of indigenous people. In W. B. Eide \& U. Kracht (Eds.), Food and Human Rights in Development: Legal and institutional. Legal and institutional dimension and selected topics (pp. 285-322). Oxford: Intersentia.

Du Rand, G. E., Heath. E. \& Alberts, N. (2003). The Role of Local and Regional Food in Destination Marketing. Journal of Travel \& Tourism Marketing, 14(3\&4), 97-112.

Dweba, T. P. \& Mearns, M. A. (2011). Conserving indigenous knowledge as the key to the current and future use of traditional vegetables. International Journal of Information Management, 3, 564-571.

Chadare, F. J., Hounhouigan, J. D., Linnemann, A. R., Nout, M. J. R. \& van Boekel, M. A. J. S. (2008). Indigenous Knowledge and Processing of Adansonia Digitata L. Food Products in Benin. Ecology of Food and Nutrition, 47(4), 338-362.

Faber, M., Oelofse, A., Van Jaarsveld, P. J., Wenhold, F. A. M. \& Jansen van Rensburg, W. S. (2010). African leafy vegetables consumed by households in the Limpopo and KwaZulu-Natal provinces in South Africa. South African Journal of Clinical Nutrition, 23(1), 30-38.

Flandrin J. L. \& Montanari, M. (1999). Conclusion. Today and tomorrow. In J. L. Flandrin \& M. Montanari (Eds.), Food: a culinary history from antiquity to the present (pp.548-553). New York: Columbia University Press.

Fox, F. W. (1974). Nutritional Value of Indigenous Plants. South African Medical Journal, 23 November, 2360-2361.

Giampiccoli, A. \& Hayward Kalis, J. (2012). Tourism, Food, and Culture: Community-Based Tourism, Local Food, and Community Development in Mpondoland. Culture, Agriculture, Food and Environment, 34(2), 101-123.

Goldstein, D. (2008). Melting Pots and Rainbows. Gastronomica, 8(2). [Online] Available: http://www.gastronomica.org/melting-potsrainbows/ (February 24, 2014).

Guyomard, H., Darcy-Vrillon, B., Esnouf, C., Marin, M., Momot, A., Russel, M. \& Guillou, M. (2011). Eating Patterns and Food Systems: Critical Knowledge Requirements for Policy Design and Implementation. Revised Version of a working document prepared for the Commission on Sustainable Agriculture and Climate Change. [Online] Available: http://ccafs.cgiar.org/sites/default/files/assets/ docs/guyomard_et_al_eating_patterns_and_food_systems.pdf (January 30, 2014).

Hall, C. M. (2003). Preface. In C. M. Hall (Ed.), Wine, Food and Tourism Marketing (pp. XIII-XXIV). Binghamton: The Haworth Hospitality Press.

Howard, P. (2003). The major importance of 'minor' Resources: women and plant Biodiversity. International Institute for Environment and Development, Natural Resources Group and Sustainable Agriculture and Rural Livelihoods Programme. Gatekeeper Series, 112, 3-19.

Jacobs, T. V. (2002). Underutilized Edible Plants from South Africa: a Perspective. In J. M. M. Engels, V. Ramanatha Rao, A. H. D. 
Brown \& M. T. Jackson (Eds.), Managing Plant Genetic Diversity (pp.371-377). International Plant Genetic Resource Institute (IPGRI). Wallingford: CABI Publishing.

Jacoby, E. \& Murillo P. (2012). The best food on earth: Peru. The union of agriculture, gastronomy, nutrition [Commentary]. World Nutrition, 3(8), 358-372.

Kepe, T. (2008). Social Dynamics of the Value of Wild Edible Leaves (Imifino) in a South African Rural Area. Ecology of Food and Nutrition, 47(6), 531-558.

Kimani-Murage, E. W., Kahn, K., Pettifor, J. M., Tollman, S. M., Dunger, D. B., Gómez-Olivé, X. F. \& Norris, S. A. (2010). The prevalence of stunting, overweight and obesity, and metabolic disease risk in rural South African children. BMC Public Health, 10(158), 1-13.

Krebs, J. R. (2009). The gourmet ape: evolution and human food preferences. American Journal of Clinical Nutrition, 90(Suppl.), 707S$711 \mathrm{~S}$.

Lambden, J., Receveur, O. \& Kuhnlein, H. V. (2007). Traditional food attributes must be included in studies of food security in the Canadian Arctic. International Journal of Circumpolar Health, 66(4),308-319.

Langgat, J., Yasin, M. S. \& Mansur, N. A. (2011). The alteration of sarawak ethnic natives' food: it's impact to sarawak state tourism. 2nd International Conference on Business and Economic Research (2nd ICBER 2011) proceeding. [Online] Available: http://www.internationalconference.com.my/proceeding/icber2011_proceeding/171-2nd\%20ICBER\%202011\%20PG\%20648698\%20Natives\%20Food.pdf (February 13, 2014).

Levy, L. F., Weintroub, D. \& Fox, F. W. (1936). The food values of some common edible leaves. South African Medical Journal, 24 October, 699-707.

Long, L. M. (2001). Nourishing the academic imagination: the use of food in teaching concepts of culture. Food and Foodways, 93(3\&4), 235-262.

Lutaladio, N., Burlingame, B. \& Crews, J. (2010). Horticulture, biodiversity and nutrition. Journal of Food Composition and Analysis, 23, 481-485.

Mak, A. H. N., Lumbers, M. \& Eves, A. (2012). Globalisation and Food Consumption in Tourism. Annals of Tourism Research, 39(1), 171-196.

Matenge, S. T., Van der Merwe, D., Kruger, A. \& De Beer, H. (2011). Utilisation of indigenous plant foods in the urban and rural communities. INDILINGA - African Journal of Indigenous Knowledge Systems, 10(1), 17-37.

Maundu, P., Achigan-Dako, E. \& Morimoto Y. (2009). Biodiversity of African Vegetables. In. C. M. Shackleton, M. W. Pasquini, \& Drescher, A. W. (Eds.), African Indigenous Vegetables in Urban Agriculture (pp.65-104). London: Earthscan.

McCann, J. C. (2010). Stirring the Pot. A history of African cuisine. London: Hurst \& Company.

Modi, A. T. (2003). What do subsistence farmers know about indigenous crops and organic farming? Preliminary experience in KwaZuluNatal. Development Southern Africa, 20(5), 675-684.

Montanari, M. (1999). Romans, Barbarians, Christians. The dawn of European food culture. In J. L. Flandrin \& M. Montanari (Eds.), Food: a culinary history from antiquity to the present (pp.165-167). New York: Columbia University Press.

Montanari, M. (2006). Food is culture. New York: Columbia University Press.

Moroka, T. (2004). In Conclusion. In B. Basemzansi (Ed.), South African Indigenous Foods. A collection of recipes of indigenous foods, prepared by generation of women (p. 95). Pretoria: IndiZAFoods.

Nesbitt, M., McBurney, R. P. H., Broin, M. \& Beentje, H. J. (2010). Linking biodiversity, food and nutrition: The importance of plant identification and nomenclature. Journal of Food Composition and Analysis, 23, 486-498.

Ngubane, B, (2004). Introduction by the Minister of Arts, Culture, Scince and Technology. In B. Basemzansi (Ed.), South African Indigenous Foods. A collection of recipes of indigenous foods, prepared by generation of women (p. 7). Pretoria: IndiZAFoods.

O' Connor, A. (2012). Conversion in Central Quintana Rio. Changes in religion, community, economyand nutrition in a Maya village. Food, Culture and Society, 15(1), 77-91.

Pasquini M. W. \& Young, E. M. (2009). Preface. . In. C. M. Shackleton, M. W. Pasquini, \& Drescher, A. W. (Eds.), African Indigenous Vegetables in Urban Agriculture (pp. XXI-XXVI). London: Earthscan.

Potter, R. B. (2002). Global convergence, divergence and development. In V. Desai \& R. B. Potter (Eds.), The Companion to Development Studies (pp 192-195). London: Arnold.

Raschke, V. \& Cheema, B. (2007). Colonisation, the New World Order, and the eradication of traditional food habits in East Africa: historical perspective on the nutrition transition. Public Health Nutrition, 11(7), 662-674.

Saayman, M. (2009). Community tourism. In M. Saayman, (Ed.), Ecotourism. Getting back to basic (pp. 67-96). Potchefstroom: Institute for tourism and Leisure Studies.

Santich, B. (2004). The study of gastronomy and its relevance to hospitality education and training. Hospitality Management, $23,15-24$.

Shava, S., O' Donoghue, R., Krasny, M. E. \& Zazu, C. (2009). Traditional food crops as a source of community resilience in Zimbabwe. International Journal of the African Renaissance, 4(1), 1-21.

Sims, R. (2009). Food, place and authenticity: local food and the sustainable tourism experience. Journal of Sustainable Tourism, 17(3), 321-336.

Smith, I. F. \& Eyzaguirre, P. (2007). African leafy vegetables: their role in the World Health Organization's global fruit and vegetable initiative. In R. Oniang'o, M. Grum \& E. Obel-Lawson (Eds.), Developing African leafy vegetables for improved nutrition. Regional workshop, 6-9 December 2005. Rural Outreach Program, Nairobi, Kenya. [Online] Available: http://www.bioversityinternational. org/uploads/tx_news/Developing_African_leafy_vegetables_for_improved_nutrition_1513.pdf (March 3, 2014). African Journal of 
Food Agriculture Nutrition and Development, 7(3\&4), 1-8.

Smith, I. F. (1995). The case for indigenous West African food culture. Breda Series, 9. UNESCO, Dakar Regional Office.

Snyman, I. (2004). South Africa's Rainbow Cuisine. Gastronomica, 4(1), 91-93.

Sonjica, B. (2004). A message from the Deputy Minister of Arts, Culture, scince and Technology. In B. Basemzansi (Ed.), South African Indigenous Foods. A collection of recipes of indigenous foods, prepared by generation of women (p. 8). Pretoria: IndiZAFoods.

Telfer, D. \& Wall, G. (1996). Linkage between tourism and food production. Annals of Tourism Research, 23(3), 635-653.

Telfer, D. J. (2000). Tastes of Niagara: Building strategic alliances between tourism and agriculture. International Journal of Hospitality and Tourism Administration, 1(1), 71-88.

Torres R. (2002). Toward a better understanding of tourism and agriculture linkages in the Yucatan: Tourist food consumption and preferences. Tourism Geographies: An International Journal of Tourism Space, Place and Environment, 4(3), 282-306.

van der Hoeven, M., Osei, J., Greeff, M., Kruger, A., Faber, M. \& Smuts, C. M. (2013). Indigenous and traditional plants: South African parents' knowledge, perceptions and uses and their children's sensory acceptance. Journal of Ethnobiology and Ethnomedicine, 9(78), 1-12.

van Rensburg, W. S, J., van Averbeke, W., Slabbert, R., Faber, M., van Jaarsveld, P., van Heerden, I., Wenhold, F \& Oelofse, A. (2007). African leafy vegetables in South Africa. Water SA, 33(3), 317-326.

Van Wyk, B. E. 2011. The potential of South African plants in the development of new food and beverage products. South African Journal of Botany, $77,857-868$.

Venter, S. L., van Rensburg, W. J., Vorster, H. J., van den Heever, E. \& van Zijl, J. J. B. (2007). Promotion of African leafy vegetables within the Agricultural Research Council - Vegetable and Ornamental Plant Institute: The impact of the project. In R. Oniang'o, M. Grum \& E. Obel-Lawson (Eds.), Developing African leafy vegetables for improved nutrition. Regional workshop, 6-9 December 2005. Rural Outreach Program, Nairobi, Kenya. [Online] Available: http://www.bioversityinternational.org/uploads/tx_news/ Developing_African_leafy_vegetables_for_improved_nutrition_1513.pdf (March 3, 2014). African Journal of Food Agriculture Nutrition and Development, 7(3\&4), 144-1499.

Vorster, I. H. J., Jansen van Rensburg, W., Van Zijl, J. J. B. \& Venter, S. L. (2007a). Re-Creating Awareness of Traditional Leafy Vegetables in Communities. In R. Oniang'o, M. Grum \& E. Obel-Lawson (Eds.), Developing African leafy vegetables for improved nutrition. Regional workshop, 6-9 December 2005. Rural Outreach Program, Nairobi, Kenya. [Online] Available: http://www.bioversityinternational.org/uploads/tx_news/Developing_African_leafy_vegetables_for_improved_nutrition_1513.pdf (March 3, 2014). African Journal of Food Agriculture Nutrition and Development, 7(3\&4), 132-136.

Vorster, I. H. J., Jansen van Rensburg, W., Van Zijl, J. J. B. \& Venter, S. L. (2007b). The Importance of Traditional Leafy Vegetables in South Africa. In R. Oniang'o, M. Grum \& E. Obel-Lawson (Eds.), Developing African leafy vegetables for improved nutrition. Regional workshop, 6-9 December 2005. Rural Outreach Program, Nairobi, Kenya. [Online] Available: http://www.bioversity international.org/uploads/tx_news/Developing_African_leafy_vegetables_for_improved_nutrition_1513.pdf (March 3, 2014). African Journal of Food Agriculture Nutrition and Development, 7(3\&4), 49-54.

Wahlqvist, M. L. (no date). Requirements for Healthy Nutrition: Integrating Food Sustainability, Food Variety and Health. [Online] Available: http://www.iuns.org/wp-content/uploads/pdf/features/Requirements_for_Healthy_Nutrition_Integrating.pdf (January 30, 2014).

Wehmeyer, A. H. \& Rose E. (1983). Important indigenous plants in the Transkei as food supplements. Bothalia, 14, 613-615. 